\title{
Publicidad, medios e independencia informativa: Pensando Chile desde la libertad de expresión
}

\author{
Faride Zeran \\ Premio Nacional de Periodismo \\ Coordinadora Programa Libertad de Expresión y Ciudadanía del ICEI \\ fzeran@uchile.cl
}

La ecuación "publicidad privada y pluralismo e independencia informativa” es el eje del presente número de la revista Comunicación y Medios, que aborda desde distintos ángulos la complejidad de una relación cuya transparencia resulta vital tanto para el ejercicio del periodismo como para la libertad de expresión.

A través de investigaciones efectuadas a la luz de casos que han impactado a la opinión pública - como el de la colusión de las cadenas farmacéuticas en Chile-, se plantea una aproximación que va desde el derecho a la información de los ciudadanos a la demanda ética tanto de los medios como de sus profesionales; así como el ineludible rol fiscalizador ante los poderes, incluyendo el económico, de quienes tienen el deber de informar.

Sin embargo, lo que desde el punto de vista de los códigos de ética del ejercicio del periodismo resulta unánime, como es el apego a principios de veracidad e independencia, es en ocasiones alterado y adquiere relevancia pública sobre todo cuando colisionan intereses que finalmente empañan las dimensiones democrática y ciudadana de nuestras sociedades.

Y ejemplos hay muchos, al menos en el Chile de la transición. Así aparece el caso de un influyente empresario dueño de una cadena de supermercados que compróla edición completa del diario La Nación Domingo, porque quedaba en evidencia el doble discurso de quien aparecía públicamente como un piadoso y conservador cristiano, mientras privadamente su esposa estampaba una denuncia ante Carabineros acusándolo de violencia intrafamiliar, como lo evidenciaba la portada del periódico.

El punto no fue solo que la edición desapareciera de los kioscos del país. Tan grave como aquello resultó el silencio de gran parte de los medios escritos y audiovisuales que demoraron casi una semana en denunciar el hecho porque, sin duda, se trataba de un poderoso avisador.

La propia Corte Interamericana de Derechos Humanos señala al respecto que: "son los medios de comunicación social los que sirven para materializar el ejercicio de la libertad de expresión, de tal modo que sus condiciones de funcionamiento deben adecuarse a los requerimientos de esa libertad. Para ello es indispensable la pluralidad de medios, la prohibición de todo monopolio respecto de ellos, cualquiera sea la forma que pretenda adoptar, y la garantía de protección a la libertad e independencia de los periodistas".

Esta premisa permite interrogarnos acerca de los niveles de conciencia de las empresas periodísticas de una especificidad que les es propia e ineludible, así como las legislaciones y 
marcos legales que existen en nuestros países para hacer más transparente y fluida una relación que afecta directamente la salud democrática de toda sociedad.

Por ello resulta relevante este número de la revista Comunicación y Medios del Instituto de Comunicación e Imagen (ICEI) de la Universidad de Chile, edición monográfica a cargo de su Programa Interdisciplinario de Libertad de Expresión y Ciudadanía. Este especial sitúa la investigación académica en la perspectiva de los derechos ciudadanos, al analizar, por ejemplo, la colusión de las farmacias y el impacto de la publicidad privada en el ejercicio del periodismo y la libertad de expresión a través de la investigación de la prensa en tres regiones de Chile, incorporando además el análisis de contenido de lo publicado en cuatro diarios de circulación nacional y tres diarios regionales.

Resulta de gran interés el comportamiento de dos actores centrales para configurar el estado de salud del derecho a la información en nuestro país.

Uno tiene relación con los periodistas y sus rutinas profesionales: formación ética y conciencia de las trampas que conducen a la autocensura; rigor investigativo, pluralidad de fuentes, cultura de la independencia y fiscalización de los poderes.

El otro actor es, sin duda, el empresariado y las normas y principios que guían su accionar.

Acerca de este último, resulta fundamental interrogarse sobre las prácticas que en plena dictadura y hasta hace no poco tiempo, le permitían ser definido como un actor altamente ideologizado, capaz de invertir en un medio no por su impacto sino por su cercanía políticavalórica, distorsionando el mito de una cierta transparencia y justicia del mercado.

Como lo demostraron numerosos estudios efectuados en los años noventa, particularmente el de Guillermo Sunkel y Esteban Geoffroy sobre la concentración de la propiedad de los medios de comunicación en Chile (2001), en materia de inversión publicitaria, los empresarios chilenos preferían avisar en medios de derecha y conservadores -aun cuando sus tirajes fueran inferiores- que en aquellos que claramente les garantizaban mayor impacto y visibilidad.

Es decir, el mercado y sus leyes no eran neutros en materia de avisaje y medios de comunicación, lo que introdujo una fuerte distorsión en el debate acerca de la creciente concentración de los medios escritos en un duopolio, versus el argumento de que medios independientes, como el desparecido diario La Época, y otros que intentaron existir en las últimas décadas, no sobrevivían porque no eran capaces de capturar a los avisadores por la calidad de su propuesta editorial.

¿Cuántas de estas conductas se han corregido hoy? ¿Cuán desterradas están las prácticas del retiro de la publicidad como sanción a un titular que disgusta al poder, como le ocurrió a The Clinic con la empresa CCU hace un par de años, o a muchos medios independientes con distintos avisadores? ¿Cuán conscientes están los empresarios de que el derecho a la información se enmarca dentro de los Derechos Humanos, lo que exige una conducta alejada de la opacidad y la manipulación?

Si la información no es una mercancía sino un derecho ciudadano, y los medios de comunicación se deben al interés público y asumen su dimensión social, la ecuación inversión 
privada, pluralismo e independencia informativa no debería constituir un conflicto sino la oportunidad de fortalecer la libertad de expresión en nuestro país.

Ello se desprende de los trabajos de investigadores del Programa Libertad de Expresión y Ciudadanía como Claudia Lagos, Laureano Checa, Cristian Cabalin y Macarena Peña y Lillo. O del estudio sobre avisaje, información y pluralismo informativo de Enrique Vergara, de la Pontificia Universidad Católica de Chile, y los académicos de la Universidad Diego Portales, Claudio Garrido, Abraham Santibáñez y Pedro Pablo Vera.

Especial relevancia cobra el estudio del profesor chileno radicado en Canadá, Claudio Durán, de York University: Publicidad y Prensa. Algunas posibles líneas de investigación. O el enfoque desde los Derechos humanos que entregan Federico Aguirre y Juan Pablo González del Instituto Nacional de Derechos Humanos, entre otros trabajos que contribuyen a enriquecer un debate esencial para la democracia y que hoy el Programa Libertad de Expresión y Ciudadanía del ICEI, entrega como parte de su misión de pensar Chile desde estos diversos campos del conocimiento. 